\title{
Analysis on the Mechanical Performance of the Joints of the Wheel-coupler type formwork Support
}

\author{
Shilong Jia ${ }^{1, a}$, Fang Zhou ${ }^{1, b}$, Zhongliang Chen ${ }^{2, ~ c ~}$ \\ ${ }^{1}$ School of Civil Engineering, Shenyang Jianzhu University, Shenyang, 110168, China \\ ${ }^{2}$ Shenyang Win Yin New Town Construction Investment Co, Ltd., Shenyang, 110000, China
}

\begin{abstract}
In order to study the mechanical properties of the joints, ANSYS software was used to simulate and analyse the failure form, ultimate bearing capacity, load-displacement curve and the rotational stiffness of the wheel-coupler joint node under force. Results: The wheel-coupler joint node has obvious non-linear characteristics when subjected to force; The bilateral symmetric tension and compression state could better reflect the failure form and deformation of the joint; The rotational stiffness of the wheel-coupler joint node under tension and bending was greater than that under bending and torsion, and was greater than that under tension, bending and torsion.
\end{abstract}

\section{Introduction}

The continuous breakthrough of high-rise and super highrise buildings has promoted the development of steel tubular scaffold. The scaffolding commonly used in domestic, such as steel tubular scaffold with couplers, cuplock steel tubular scaffolding and disk lock steel tubular scaffold [1]. The steel tubular scaffold with couplers is gradually eliminated in domestic and foreign markets due to its weaker mechanical properties. While cuplock steel tubular scaffolding has better mechanical properties than the steel tubular scaffold with couplers, but uses a larger amount of steel [2]. The wheel-coupler type formwork support is a new type of disk lock steel tubular scaffold, the upright tube is welded with a wheel-coupler plate, and the two ends of the ledger are welded with plugs. When the wheel-coupler type formwork support is installed, it can be locked by inserting the plug into the socket of the wheel-coupler plate and hammering the plug downward. The erection and demolition speed are fast, which is 8-10 times that of steel tubular scaffold with couplers and more than twice that of cuplock steel tubular scaffolding [3]. Moreover, it is cheap and has good mechanical properties, which can be used instead of other scaffoldings in practical engineering.

At present, many scholars have conducted a lot of experimental research and theoretical analysis on the overall mechanical properties of the wheel-coupler type formwork support [3-6]. However, the research on the mechanical properties of the joints is insufficient and limited to the unilateral force performance research of the joints [7-9], so it is urgent to conduct related theoretical analysis and experimental research on the mechanical properties of the nodes.

\section{Finite element establishment}

The solid modeling of wheel-couplers type formwork support components is carried out by ANSYS software, as shown in Fig.1. The solid element Solid187 is selected for the unit type. The upper and lower ends of the upright tube are fixed, and two sets of contact pairs are set up, which are the contact between the wheel-coupler plate and the plug, and the contact between the upright tube and the plug. The four sides of the plug are set as contact surface, the inner surface of the socket of the wheel-coupler plate and the outer surface of the upright tube are set as the target surface. The contact unit is CONTA174 unit and TARGE170 unit, and the friction coefficient is set as 0.15 .

The finite element verification of Wang Zhouchun's joint bending test is carried out [9]. The model materials are Q235, the modulus of elasticity is $2.06 \times 10^{5} \mathrm{MPa}$, the Poisson's ratio is 0.3 , the yield strength is $235 \mathrm{MPa}$, and the upright tube and ledger are $ø 48 \times 3.5$ steel tube. The comparison with the load-displacement results of the finite element is shown in Fig.2. The comparative analysis of the finite element and experimental results show that the results are more consistent, indicating that the boundary conditions and contact settings of the modeling in this paper are correct.

a email: cesljia@sjzu.edu.cn, ${ }^{\mathrm{b}}$ email: 1054770837@qq.com, ${ }^{\mathrm{c}}$ email: 2846491929@qq.com 


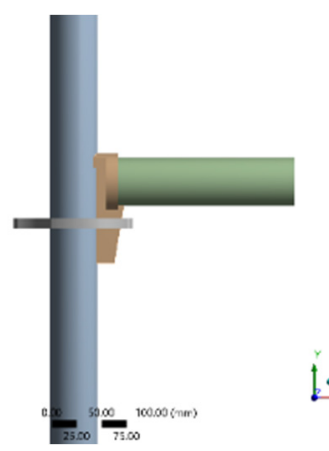

Fig. 1. finite element model

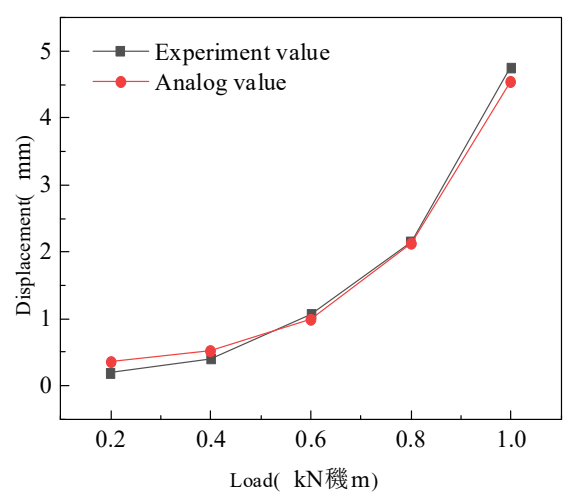

Fig. 2. Comparison curve of experimental value and simulated value

\section{The simulation analysis of the connection performance of the wheel- coupler joint node}

The material of the model is selected with reference to the specification T/CCIAT 0003-2019 [10], the upright tube and ledger of the model are respectively $ø 48.3 \times 3.6$ and $\varnothing 48.3 \times 3.0$ steel pipes, and the material is Q235 steel, the elastic modulus $E$ is $2.06 \times 10^{5} \mathrm{MPa}$, the Poisson's ratio is 0.3 , and the yield strength is $235 \mathrm{MPa}$; The plug and the wheel-coupler plate are made of ZG270-500 cast steel material, the modulus of elastic is $2.02 \times 10^{5} \mathrm{MPa}$, the Poisson's ratio is 0.3 , the yield strength is $270 \mathrm{MPa}$, the tangent modulus after yield is $0.01 E$. The analysis adopts large deformation theory, Von Mises yield criterion and Bilinear Kinematic Hardening Model.

\subsection{Finite element analysis of joint tension}

Establish finite element models of unilateral tension, bilateral symmetric tension, and bilateral asymmetric tension, as shown in Fig.3. Fix the upper and lower ends of the upright tube, and apply tension to the end face of the ledgers.

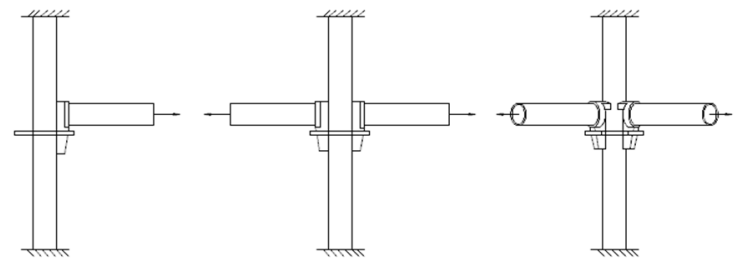

Fig.3. Schematic diagram of node tensile model
Taking the model of bilateral symmetric tension as an example, the results are as follows:

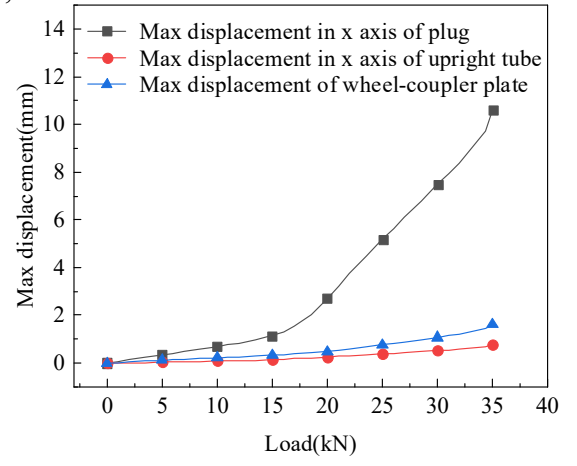

Fig.4. Load-displacement curve of bi-symmetric tension

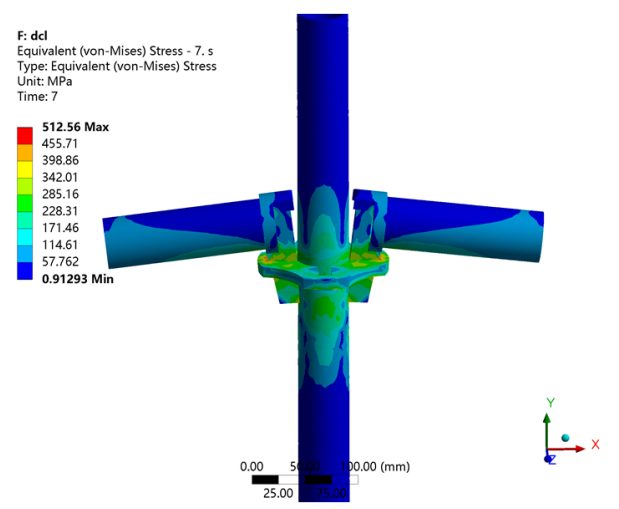

Fig.5. Stress cloud chart under bi-symmetric tension

In tension, the load-displacement curve of the joint is composed of linear stage and nonlinear stage, and the load from the linear stage to the nonlinear stage is used as the serviceability limit states load. The maximum stress of unilateral tension and bilateral symmetric tension are distributed in the contact area of the plug and the wheelcoupler plate; The maximum stress of bilateral asymmetric tension is distributed in the contact area between the plug and the wheel-coupler plate, and the contact area between the wheel-coupler plate and the upright tube. The failure form of bilateral symmetric tension is that the edge of the wheel-coupler plate socket is broken, and the plug is bent and deformed; The failure forms of unilateral and bilateral asymmetric tension are that the edge of the wheel-coupler plate socket is broken, the upright tube and plug are bent and deformed, so the bilateral symmetric tension can better reflect the tensile deformation of the wheel-coupler joint node. The serviceability limit states load of the wheel-coupler joint node under unilateral tension, bilateral symmetric and bilateral asymmetric tension are $25 \mathrm{kN}, 20 \mathrm{kN}$ and $15 \mathrm{kN}$, respectively, and the load of the ultimate limit states are $30 \mathrm{kN}, 35 \mathrm{kN}$ and $25 \mathrm{kN}$.

\subsection{Finite element analysis of node compression}

Establish finite element models of unilateral compression, bilateral symmetric compression, bilateral asymmetric compression, as shown in Fig.6. Fix the upper and lower ends of the upright tube, and apply compression to the end face of the ledgers. 

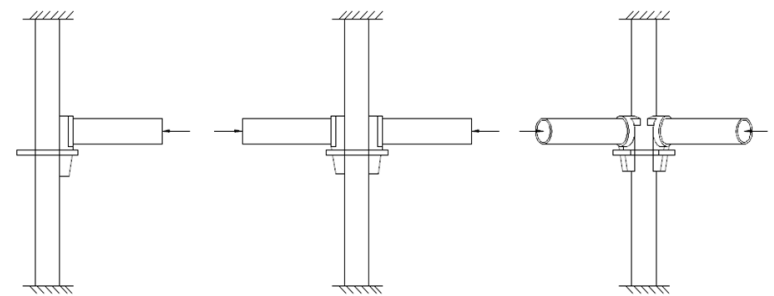

Fig.6. Schematic diagram of node compression model

Taking the model of bilateral symmetric compression as an example, the results are as follows:

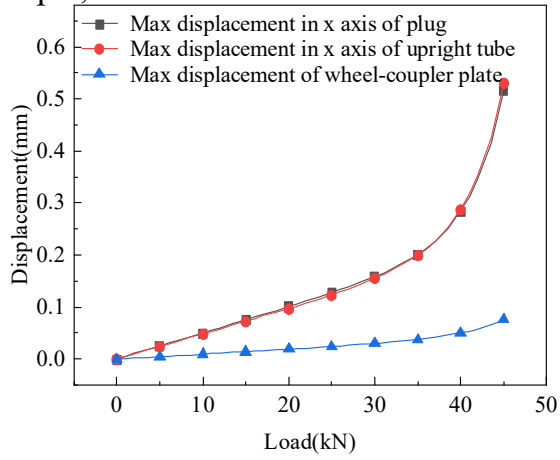

Fig.7. Load-displacement curve of bi-symmetric compression

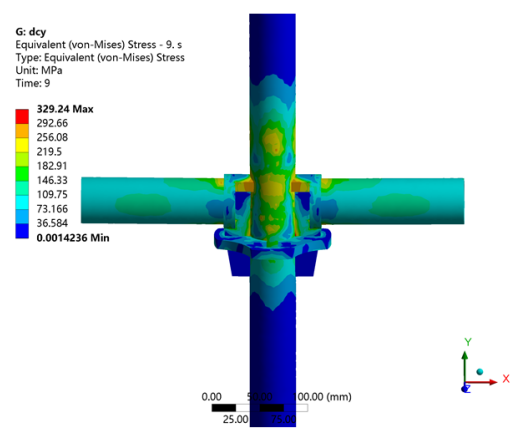

Fig.8. Stress cloud chart under bi-symmetric compression

The load-displacement curve of the wheel-coupler joint node under compression is similar to the tensile state, and has obvious nonlinear characteristics. The maximum stress under unilateral compression is distributed in the contact area between the upper part of the plug and the upright tube, while the maximum stress under bilateral symmetric and asymmetric compression are distributed in the contact area between the upright tube and the upper part of the plug and the upright tube area between the two plugs. The failure mode of bilateral symmetric compression is mainly that the upright tube is squeezed, the cross section is flattened, and the plug becomes loose due to the enlarged socket; The failure modes of unilateral compression and bilateral asymmetric compression are mainly that the upright tube is compressed and produces large bending deformation. There are no obvious deformation of wheel-coupler plate and plug under compression, and bilateral symmetric compression can better reflect the compression deformation of wheelcoupler joint node. Under unilateral, bilateral symmetric and bilateral asymmetric compression, the serviceability limit states load of the wheel-coupler joint node are $30 \mathrm{kN}$,
$35 \mathrm{kN}$ and $20 \mathrm{kN}$, respectively, and the load of ultimate limit states are $35 \mathrm{kN}, 45 \mathrm{kN}$ and $25 \mathrm{kN}$.

\subsection{Calculation of node bending stiffness value}

Steel tubular scaffold joint belongs to semi-rigid connection, and the bending stiffness value can well measure the semi-rigid characteristics of the joints [11]. Fix the upper and lower ends of the upright tube, and apply vertical force at a distance of $1000 \mathrm{~mm}$ from the center line of the upright tube, as shown in Fig. 9.

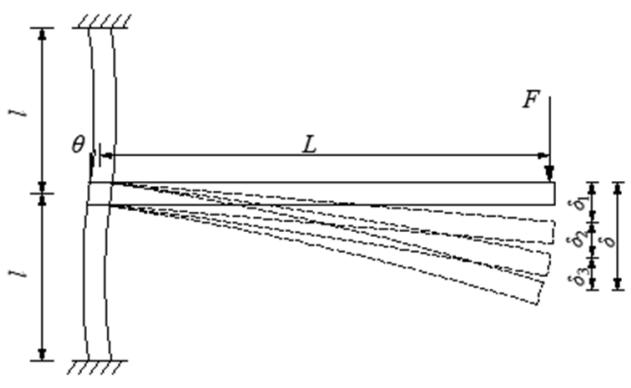

Fig.9. The force diagram of node

The displacement $\delta=\delta_{1}+\delta_{2}+\delta_{3}$, which is caused by ledger rotation, the $\delta_{1}$ is the joint angular displacement, and $\delta_{2}, \delta_{3}$ are the flexible deformation displacements of the upright tube and ledger, respectively. From formulas (1), (2), (3), the relative rotation angle $\theta_{1}$ of the wheel-coupler joint node can be calculated.

$$
\begin{gathered}
\delta_{2}=\frac{F L^{3}}{3 E I} \\
\delta_{3}=\frac{F L^{2} l}{8 E I} \\
\theta_{1}=\frac{\delta_{1}}{L}=\frac{\delta-\delta_{2}-\delta_{3}}{L}
\end{gathered}
$$

Where $L=1000 \mathrm{~mm}, l=250 \mathrm{~mm}$. The formulas for secant stiffness and the tangent stiffness of the wheel-coupler joint node are shown in (4) and (5):

$$
\begin{aligned}
& \text { secant stiffness }=\frac{M}{\theta_{1}} \\
& \text { tangent stiffness }=\frac{\Delta M}{\Delta \theta_{1}}
\end{aligned}
$$

Calculation of stiffness of wheel-coupler joint node under different bending states by formula (4) and (5), as shown in table 1-3.

Table 1 Tension and bending stiffness of joint

\begin{tabular}{|c|c|c|c|}
\hline $\begin{array}{c}M \\
(\mathrm{kN} \cdot \mathrm{m})\end{array}$ & $\theta(\mathrm{rad})$ & $\begin{array}{c}\text { Secant } \\
\text { stiffness } \\
(\mathrm{kN} \cdot \mathrm{m} / \mathrm{rad})\end{array}$ & $\begin{array}{c}\text { Tangent } \\
\text { stiffness } \\
(\mathrm{kN} \cdot \mathrm{m} / \mathrm{rad})\end{array}$ \\
\hline 0.1 & 0.003011 & 33.21 & 33.21 \\
\hline 0.2 & 0.006024 & 33.20 & 33.19 \\
\hline 0.3 & 0.009122 & 32.89 & 32.28 \\
\hline
\end{tabular}




\begin{tabular}{|l|l|l|l|}
\hline 0.4 & 0.012994 & 30.78 & 25.83 \\
\hline 0.5 & 0.019770 & 25.29 & 14.76 \\
\hline 0.6 & 0.036962 & 16.23 & 5.82 \\
\hline
\end{tabular}

When the wheel-coupler joint node is under tension and bending, the initial rotational stiffness in the elastic stage is $33.21 \mathrm{kN} \cdot \mathrm{m} / \mathrm{rad}$, the bending stiffness in the elastic-plastic stage is $16.23 \sim 33.20 \mathrm{kN} \cdot \mathrm{m} / \mathrm{rad}$, and the bending stiffness in the plastic stage is $0 \sim 16.23 \mathrm{kN} \cdot \mathrm{m} / \mathrm{rad}$.

Table 2 Bending and torsional stiffness of joint

\begin{tabular}{|c|c|c|c|}
\hline $\begin{array}{c}M \\
(\mathrm{kN} \cdot \mathrm{m})\end{array}$ & $\theta(\mathrm{rad})$ & $\begin{array}{c}\text { Secant } \\
\text { stiffness } \\
\mathrm{kN} \cdot \mathrm{m} / \mathrm{rad})\end{array}$ & $\begin{array}{c}\text { Tangent } \\
\text { stiffness } \\
(\mathrm{kN} \cdot \mathrm{m} / \mathrm{rad})\end{array}$ \\
\hline 0.1 & 0.004048 & 24.71 & 24.71 \\
\hline 0.2 & 0.008188 & 24.43 & 24.15 \\
\hline 0.3 & 0.013684 & 21.92 & 18.20 \\
\hline 0.4 & 0.026865 & 14.89 & 7.59 \\
\hline
\end{tabular}

When the wheel-coupler joint node is under bending and torsion, the initial rotational stiffness in the elastic stage is $24.71 \mathrm{kN} \cdot \mathrm{m} / \mathrm{rad}$, which is lower than that of under tension and bending. The bending stiffness in the elasticplastic stage is $14.89 \sim 24.43 \mathrm{kN} \cdot \mathrm{m} / \mathrm{rad}$, and in the plastic stage, the bending stiffness is $0 \sim 14.89 \mathrm{kN} \cdot \mathrm{m} / \mathrm{rad}$.

Table 3 Tension, bending and torsion stiffness of joint

\begin{tabular}{|c|c|c|c|}
\hline $\begin{array}{c}M \\
\mathrm{kN} \cdot \mathrm{m})\end{array}$ & $\theta(\mathrm{rad})$ & $\begin{array}{c}\text { Secant stiffness } \\
(\mathrm{kN} \cdot \mathrm{m} / \mathrm{rad})\end{array}$ & $\begin{array}{c}\text { Tangent } \\
\text { stiffness } \\
(\mathrm{kN} \cdot \mathrm{m} / \mathrm{rad})\end{array}$ \\
\hline 0.07 & 0.002810 & 25.16 & 25.16 \\
\hline 0.14 & 0.005617 & 25.18 & 18.85 \\
\hline 0.21 & 0.008420 & 25.19 & 18.87 \\
\hline 0.28 & 0.011351 & 24.91 & 17.79 \\
\hline 0.35 & 0.014761 & 23.95 & 15.19 \\
\hline 0.42 & 0.020555 & 20.64 & 8.04 \\
\hline
\end{tabular}

When the wheel-coupler joint node is under tension, bending and torsion, the initial rotational stiffness of joint is $25.16 \mathrm{kN} \cdot \mathrm{m} / \mathrm{rad}$, which is lower than that under tension and bending, and higher than that under bending and torsion. The bending stiffness of elastic-plastic stage is between $20.64 \sim 25.18 \mathrm{kN} \cdot \mathrm{m} / \mathrm{rad}$, and the bending stiffness of plastic stage is between $0 \sim 20.64 \mathrm{kN} \cdot \mathrm{m} / \mathrm{rad}$.

\section{Conclusion}

(1) The numerical analysis in this paper is in good agreement with the experimental results, indicating that the boundary conditions and contact analysis settings of the established finite element model are correct.

(2) The load-displacement curves of wheel-coupler joint node show obvious nonlinear characteristics when under tension, compression and bending.

(3) When the wheel-coupler joint node is under unilateral tension and bilateral asymmetric tension, the main forms of failure are that the edge of the wheelcoupler plate is damaged, and the plug and upright tube are bent; The main failure forms of bilateral symmetric tension is that the edge of the wheel-coupler plate is broken, the plug is bent, and the upright tube has no obvious deformation. When the wheel-coupler joint node is under unilateral compression and bilateral asymmetric compression, the main forms of failure are that the upright tube is bend and squashed; When bilateral symmetric compression, the upright tube is squashed without bending deformation. Bilateral symmetric tension and compression can better reflect the deformation and failure forms of joint.

(4) The initial rotational stiffness of the wheel-coupler joint node under tension and bending is $33.21 \mathrm{kN} \cdot \mathrm{m} / \mathrm{rad}$, which is greater than that under tension, bending and torsion, and greater than that under bending and tension.

\section{Acknowledgments}

The authors wish to thank Science and technology program of the Educational Department of Liaoning Province, China (lnjc201905) for sponsoring this research project.

\section{References}

1. Cheng Y. (2017) Performance Research of Wheelcoupler Type Steel Tubular Scaffolding, South China University of Technology, Guangzhou.

2. Wang F Q. (2019) Introduction of technical specification for safety of wheel-coupler type formwork support in construction. Building Science, 35:122125.

3. Wang X. (2017) The research on development and applied of the new wheel buckle scaffold support frame Hebei University of Science and Technology, Hebei.

4. Yang Y D. (2012) The Research on the Complete Equivalent Initial Imperfection Formwork Supporting Frame with Pulley-clip Style. Changsha University of Science and Technology, Hunan.

5. Yu Y. (2019) Experimental study on the bearing capacity of the new wheel buckle formwork support frame system. Hebei University of Science and Technology, Hebei.

6. Huang J. (2019) Research on the engineering application of the new wheel buckle formwork support frame system, Hebei University of Science and Technology, Hebei.

7. Chen M, Yan X M. Zhao R, Zheng Y D, Quan B L, Chen P M, Sun Q Q. (2019) Comparative Study on Stiffness for Wheel-buckled and Fastener-type Tubular Support Formwork Joint. Construction Technology, 48: 60-65.

8. Bai S H. (2018) Research on the Connection Node Mechanical Properties of wheel-coupler Type Steel 
Tube Formwork Support. Changsha University of Science and Technology, Hunan.

9. Wang Z C. (2013) The experimental investigation of socket type steel pipe scaffold. Hunan University, Hunan.

10. CCIA. (2019) Technical specification for safety of wheel-coupler type formwork support in construction. China Architecture and Building Press, Beijing.

11. Yang M, Fang S S, Chen S Q. (2018) Research on bending resistance performance of cross-plate steel scaffold joint. Journal of Hefei University of Technology, 41:833-837 